\title{
Different neural substrates for precision stepping and fast online step adjustments in youth
}

\author{
Sharissa H. A. Corporaal ${ }^{1}$. Sjoerd M. Bruijn ${ }^{1,2} \cdot$ Wouter Hoogkamer $^{1,3} \cdot$ Sima Chalavi $^{1} \cdot$ Matthieu P. Boisgontier $^{1}$. \\ Jacques Duysens ${ }^{1} \cdot$ Stephan P. Swinnen ${ }^{1,4}$. Jolien Gooijers ${ }^{1}$
}

Received: 16 August 2017 / Accepted: 30 November 2017 / Published online: 24 January 2018

(c) The Author(s) 2017. This article is an open access publication

\begin{abstract}
Humans can navigate through challenging environments (e.g., cluttered or uneven terrains) by modifying their preferred gait pattern (e.g., step length, step width, or speed). Growing behavioral and neuroimaging evidence suggests that the ability to modify preferred step patterns requires the recruitment of cognitive resources. In children, it is argued that prolonged development of complex gait is related to the ongoing development of involved brain regions, but this has not been directly investigated yet. Here, we aimed to elucidate the relationship between structural brain properties and complex gait in youth aged 9-18 years. We used volumetric analyses of cortical grey matter (GM) and whole-brain voxelwise statistical analyses of white matter (WM), and utilized a treadmill-based precision stepping task to investigate complex gait. Moreover, precision stepping was performed on step targets which were either unperturbed or perturbed (i.e., unexpectedly shifting to a new location). Our main findings revealed that larger unperturbed precision step error was associated with decreased WM microstructural organization of tracts that are particularly associated with attentional and visual processing functions. These results strengthen the hypothesis that precision stepping on unperturbed step targets is driven by cortical processes. In contrast, no significant correlations were found between perturbed precision stepping and cortical structures, indicating that other (neural) mechanisms may be more important for this type of stepping.
\end{abstract}

Keywords Childhood development $\cdot$ Adolescence $\cdot$ Brain $\cdot$ White matter $\cdot$ Precision stepping $\cdot$ Locomotion

$\begin{array}{ll}\text { Abbreviations } \\ \text { AD } & \text { Axial diffusivity } \\ \text { ARD } & \text { Available response distance } \\ \text { ATR } & \text { Anterior thalamic radiation } \\ \text { COP } & \text { Center of pressure } \\ \text { FA } & \text { Fractional anisotropy } \\ \text { FDR } & \text { False discovery rate } \\ \text { GM } & \text { Grey matter }\end{array}$

Jolien Gooijers

jolien.gooijers@kuleuven.be

1 Movement Control and Neuroplasticity Research Group, Department of Movement Sciences, KU Leuven, Tervuursevest 101, box 1501, 3001 Leuven, Belgium

2 Department of Human Movement Sciences, MOVE Research Institute Amsterdam, VU University Amsterdam, Amsterdam, The Netherlands

3 Department of Integrative Physiology, University of Colorado, Boulder, USA

4 Leuven Research Institute for Neuroscience and Disease (LIND), KU Leuven, Leuven, Belgium

$\begin{array}{ll}\text { ICV } & \text { Intracranial volume } \\ \text { MD } & \text { Mean diffusivity } \\ \text { MNI } & \text { Montreal neurological institute common coordi- } \\ & \text { nate space } \\ \text { RD } & \text { Radial diffusivity } \\ \text { ROI } & \text { Regions of interest } \\ \text { SLF } & \text { Superior longitudinal fasciculus } \\ \text { STS } & \text { Superior temporal sulcus } \\ \text { WM } & \text { White matter }\end{array}$

\section{Introduction}

During childhood, walking (gait) skills are developed, going from independent but very unstable gait at infancy (10-18 months of age; Forssberg 1985), to adult-like gait patterns around 8 years of age. This is reflected by matured step speed, step length, stride length, and temporal variability of step cycle duration (Hausdorff et al. 1999; Vaughan et al. 2003; Dusing and Thorpe 2007; Froehle et al. 2013). This holds, however, only for simple forms of gait (i.e., 
'basic gait'), in which the preferred gait pattern can be maintained. Basic gait is rare in everyday life, as humans normally walk through challenging environments (e.g., cluttered or uneven terrains), possibly with obstacles that force the modification of the preferred gait pattern (i.e., 'complex gait'). Studies illustrate an ongoing refinement of complex gait strategies after the age of 8 years during complex gait tasks such as obstacle avoidance, precision stepping, and dual-task walking. This refinement is reflected by improving gait speed and obstacle clearance (Pryde et al. 1997; Michel et al. 2010), the presence of adult-like muscle activations (McFadyen et al. 2001), and more efficient foot placements (Berard and Vallis 2006; Choi et al. 2016; Corporaal et al. 2016). It has been suggested, but not established, that this extended refinement relates to ongoing neural maturation of cognitive processes underlying the control of complex gait (e.g., Pryde et al. 1997; Choi et al. 2016; Corporaal et al. 2016).

A recent systematic review on brain activation during imagined walking using MRI/fMRI or during real walking using measurement systems such as fNIRS, EEG, and PET (Hamacher et al. 2015) gave an extensive overview of brain areas involved during walking. Although a large network of brain areas is active during walking and walking imagery compared to standing [e.g., supplementary motor area (SMA), primary motor cortex, prefrontal cortex, premotor cortex, cingulate cortex, temporal gyrus, occipital cortex, parietal area, (pre)cuneus, thalamus, parahippocampal gyrus, putamen, globus pallidus, mesencephalic locomotor region, and cerebellum], the main message of this review article is that the level of involvement of the various brain regions depends on the specific task, its level of complexity, patient's pathology and/or participant's age. Specifically, gait tasks with a higher complexity level are more likely to be associated with increased activation in prefrontal areas, SMA and areas involved in multisensory processing (Hamacher et al. 2015). Thus, a wide range of cortical areas should probably be matured/developed to perform skilled, complex gait.

Considering the structural maturation of GM brain regions which are involved during gait and their WM connections, it has been shown that higher order brain regions (e.g., prefrontal cortices associated with complex gait) generally mature later than lower order brain regions (e.g., sensorimotor cortices associated with basic gait) (Sowell et al. 1999; Gogtay et al. 2004; Casey et al. 2005; Paus 2005; Kochunov et al. 2012; Ducharme et al. 2016). Although the exact age at which both maturation processes (WM and GM) are completed remains unclear, they appear to evolve until around 30 years of age (Giedd et al. 1999; Lenroot and Giedd 2006; Ostby et al. 2009; Lebel and Beaulieu 2011; Raznahan et al. 2011, 2014; Yap et al. 2013; Herting et al. 2015; Ducharme et al. 2016). In general, such developmental brain changes are characterized by decreasing GM volume and increasing WM volume, which is likely related to biological processes such as synaptic pruning and myelination, respectively (Huttenlocher 1990; Giedd et al. 1999; Lenroot and Giedd 2006; Petanjek et al. 2008; Yap et al. 2013; Kostovic et al. 2014).

These hierarchical maturation patterns of higher versus lower level brain regions seem to concur with the development of complex versus basic gait. Although studies in children are lacking, studies in older adults have illustrated the impact of age-related structural brain decline on gait. For instance, smaller GM volumes of sensorimotor and frontoparietal regions were associated with shorter steps and longer double support times (Rosano et al. 2008), smaller prefrontal GM volumes with lower gait speed (Rosano et al. 2012), and smaller parietal GM volume with larger variability of stride length (Beauchet et al. 2014). In addition, disrupted WM properties have been associated with poorer gait performance in older adults (Bhadelia et al. 2009; de Laat et al. 2011; Koo et al. 2012; Bruijn et al. 2014). For example, decreased microstructural organization of the corticospinal tract and thalamic radiation was related to decreased gait stability (Bruijn et al. 2014), and decreased organization of the genu of the corpus callosum with decreased gait performance, as measured with Tinetti gait scores (Bhadelia et al. 2009). Translating these findings to childhood development, it may be possible that immature brain structures impact complex gait performance in children.

Therefore, the primary aim of the present study was to investigate the impact of structural brain changes on complex gait skills in youth aged 9-18 years. We challenged gait control by projecting step targets onto a treadmill, similar to tests used by other members of our group (Potocanac et al. 2014; Hoogkamer et al. 2015; Mazaheri et al. 2015). The complexity of precision stepping was manipulated by occasionally and unexpectedly shifting step targets to new locations during the execution phase of the step. On a behavioral level, we hypothesized that step accuracy would improve with age, yet deteriorate with higher levels of complexity. This would be reflected by decreasing step error and step variability with age, and increasing step error and step variability for the higher levels of complexity. Combining brain and behavior, we hypothesized that step accuracy would improve with whole-brain structural maturation (decreased GM volume, increased WM microstructural organization). We also explored whether the maturation of higher order brain areas involved in motor planning and attention (e.g., frontal areas) are relevant for precision stepping performances. Moreover, these neurobehavioral relationships were assumed to be more pronounced with increasing task complexity. This study is a preliminary step towards understanding the structural neural underpinnings of complex sensorimotor tasks. 


\section{Methods}

\section{Participants}

Thirty participants were included for behavioral data analyses (13 females; age range 9.0-18.5 years; mean age $14.4 \pm 2.6$ years). All participants received a brain scan for GM and WM analyses. For both GM $(N=28,13$ females, age range 9.0-17.9; mean age 14.2 \pm 2.6 ), and WM analyses $(N=28,13$ females, age range 9.0-18.4; mean age $14.5 \pm 2.6$ ), two (different) male participants were excluded due to excessive head motion and/or technical problems during imaging acquisition. All participants were right-handed as indicated by the Oldfield Handedness scale (Oldfield 1971) (mean: 0.79, SD: 0.19, range: 0.08-1). Most participants reported a right-foot preference, although one participant (15.83 years, male) reported a left-foot preference, and three participants ( 14.43 years, female; 15.77 years, female; 11.64 years, male) reported ambiguous foot preference. Participants reported no neurological, muscular, or cognitive disorders, and were screened for MRI compatibility (i.e., no MRI-incompatible implants, dental braces, and claustrophobia). All procedures performed were in accordance with the ethical standards of the local ethics committee of the KU Leuven, Belgium, and with the 1964 Helsinki declaration and its later amendments or comparable ethical standards. Informed consent was obtained from all individual participants included in the study and their parents. Participants were financially compensated for participation.

\section{Experimental setup}

The participants walked on an instrumented treadmill with an embedded force platform (C-Mill, ForceLink, Culemburg, The Netherlands) allowing for online detection of gait events based on ground reaction forces $(1000 \mathrm{~Hz}$ sampling rate) (Roerdink et al. 2008). The treadmill was equipped with a projector (Hitachi CP-A100) to present step targets onto the walking surface, adjusted to the participants' preferred gait pattern (van Ooijen et al. 2013; Potocanac et al. 2014; Hoogkamer et al. 2015; Mazaheri et al. 2015). Furthermore, ten infrared cameras (Vicon Nexus version 1.8.5; 150 samples/s) registered the position of six reflective markers, which were attached to the shoes of the participant, on locations corresponding to the third metatarsal head, lateral malleolus, and heel of each foot. During the experiment, participants wore a safety harness that was fixed to the ceiling to protect them from falling.

\section{Procedure}

After a familiarization period of $5-10 \mathrm{~min}$ at $3 \mathrm{~km} / \mathrm{h}$ of treadmill walking, in which no step targets were projected, ground reaction forces were obtained from 20 normal strides at $3 \mathrm{~km} / \mathrm{h}$. From these forces, the center of pressure (COP) trajectory was calculated, and used to extract foot-strike events, toe-off events, and step lengths (Roerdink et al. 2008). The obtained step length represented the 'preferred' step length during unperturbed treadmill walking, which was subsequently used to set the anteroposterior center-to-center distance between step targets in the experimental trials. During these experimental trials, participants were required to step as accurately as possible on the step targets projected on the treadmill. The step targets were scaled to the size of the shoe (shoe length by shoe width). Due to technical constraints (use of split belt), the mediolateral center-to-center distance between the targets was set to $20 \mathrm{~cm}$ for all participants (Fig. 1). None of the participants reported problems with these step widths.

Projection of the step targets started at $2 \mathrm{~m}$ in front of the participants, and approached the participants corresponding to the belt speed $(3 \mathrm{~km} / \mathrm{h})$. Participants were instructed to place their feet on the step targets as accurately as possible. Participants performed a maximum of two practice trials to familiarize themselves with the precision stepping procedure (59 step targets per trial).

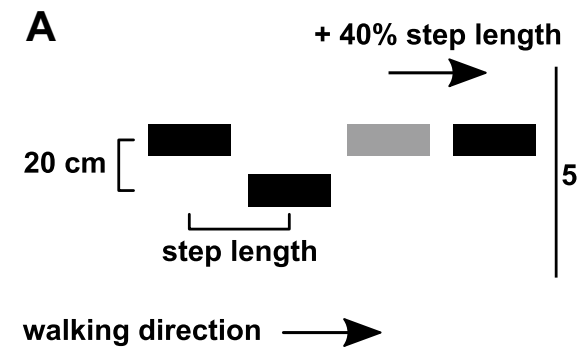

Fig. 1 Schematic overview of the step targets and their shifts in forward-backward direction (Adapted from Mazaheri et al. 2015). The distance between the step targets was determined based on participant's preferred step length. At random moments (separated by 5-7

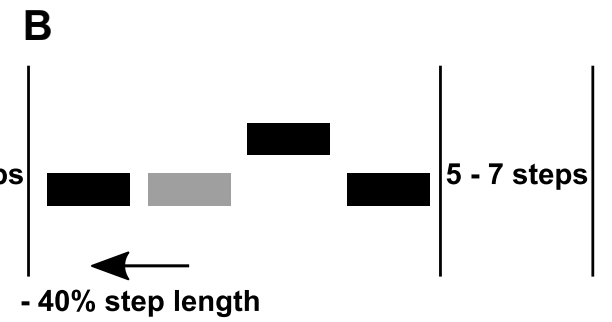

non-shifted steps), a step target could shift forwards ( $+40 \%$ of step length) or backwards ( $-40 \%$ of step length), requiring a longer step (a) or shorter-step (b) response. The shift targeted either the right or left leg 
During the experiment, four blocks of step targets were randomly presented. One block consisted of a series of 59 non-shifting step targets, allowing the assessment of stepping precision on unperturbed step targets. In the remaining three blocks, a series of 248 step targets each was presented. Some of these targets occasionally shifted to a predefined new position corresponding to $40 \%$ of the preferred step length forwards or backwards (perturbed precision stepping) (Fig. 1). Shifted targets were presented for both the left and right foot and were separated by five-to-seven non-shifted targets. Forward shifts could occur when the target was at different distances from the participant's COP, resulting in four "available response distances" (ARD) conditions of 80, 100,130 , and $200 \%$ of the preferred step length (Potocanac et al. 2014; Hoogkamer et al. 2015; Mazaheri et al. 2015). The shorter the ARDs were, the faster the step corrections had to be made. We, therefore, assumed that shorter ARDs increased the difficulty of making accurate step adjustments (Hoogkamer et al. 2015). Backward shifts only occurred at ARD of $130 \%$, and were solely used to limit anticipation to the direction of the gait perturbations. Hence, backward shifts were not analyzed. Each ARD shift was repeated 8 times ( 4 per foot), with a total of 5 ( 4 forwards +1 backwards) $\times 8=40$ target shifts per block. Participants were told in advance whether the block contained shifting targets or not, but were naïve to the exact timing of these perturbations.

\section{Data analyses}

Stepping accuracy on step targets was defined by two error measures, namely, the constant error (step error) and variability (step variability). Step error was defined as the anteroposterior distance between the centers of the targeting foot and the step target at midstance. First, the moment of midstance was obtained during the single stance phase of the foot, i.e., at $50 \%$ between toe off and heel strike of the contralateral foot. Second, the center of the foot was defined using the 3D coordinates of the foot markers at the moment of midstance. The lines connecting the foot markers at the heel, toe, and malleolus were used as a representation of the foot at midstance. Subsequently, the center of these connecting lines was defined as the center of the foot. The location of the step target's center at the moment of midstance was extracted from the C-mill software. Positive error measures indicated overshoots of the step targets (i.e., the center of the foot landed anterior to the center of the step target), while negative values indicated undershoots of the step targets (i.e., the center of the foot landed posterior to the center of the step target).

For unperturbed precision stepping, the step errors of all unperturbed steps within the unperturbed trials were averaged and subsequently normalized to preferred step length, resulting in the unperturbed step error. For perturbed precision stepping, the step errors of perturbed steps within the perturbed trials were averaged (per ARD condition) and subsequently normalized to preferred step length, resulting in the perturbed step error.

In addition, we calculated the variability of both unperturbed and perturbed steps according to the following formula:

Variability $=\sqrt{\frac{\sum \text { step error }{ }^{2}-\frac{(\Sigma \text { step error })^{2}}{k}}{k}} \%$ preferred step length

in which step error represents the step error per step (nonaveraged and non-corrected for step length) in each condition, and $\mathrm{k}$ is the number of steps analyzed. Variability was expressed as the percentage of preferred step length.

\section{Image acquisition and analyses}

\section{Image acquisition}

A Philips Ingenia 3T CX MRI scanner with a standard 32 channel head coil was used for image acquisition. For all participants, a high-resolution T1-weighted structural image was acquired using MPRAGE $(\mathrm{TR}=9.71 \mathrm{~ms}, \mathrm{TE}=4.60 \mathrm{~ms}$, $0.98 \times 0.98 \times 1 \mathrm{~mm}^{3}$ voxels, field of view $=210.94 \times 230$ $\mathrm{mm}^{2}, 230$ sagittal slices) for anatomical detail. In addition, single-shell diffusion-weighted images were acquired using the following parameters: single-shot spin echo; slice thickness $=2.5 \mathrm{~mm}$; TR $=7600 \mathrm{~ms}$; $\mathrm{TE}=65 \mathrm{~ms}$, number of diffusion directions $=60$, number of sagittal slices $=58$, voxel size $=2.5 \times 2.5 \times 2.5 \mathrm{~mm}^{3}$; diffusion weighting of $b=1300$; one non-diffusion-weighted image.

\section{Cortical grey matter: volume processing}

Cortical reconstruction and volumetric segmentation were performed using the FreeSurfer image analysis suite (v5.1; http://surfer.nmr.mgh.harvard.edu/). From the T1-weighted images, cortical volume $\left(\mathrm{mm}^{3}\right)$ measures were extracted. Details of these procedures were described in prior publications (Dale et al. 1999; Fischl and Dale 2000; Fischl et al. 2002, 2004a, b). Briefly, this procedure included motion correction of the raw T1-weighted images (Reuter et al. 2010), brain extraction, and Talairach transformation. Then, WM and GM were segmented (Fischl and Dale 2000; Fischl et al. 2004a) and intensity inhomogeneities were normalized (Sled et al. 1998). The GM/WM boundary was tessellated and the surface was deformed following intensity gradients to optimally place the GM/WM and GM/cerebrospinal fluids borders at the location, where the greatest shift in intensity defines the transition to the other tissue class (Dale and Sereno 1993; Dale et al. 1999; Fischl and Dale 2000). Once the cortical models were completed, a refinement procedure was 
applied to obtain a representation of the GM/WM boundary. This surface was subsequently deformed outwards to obtain an explicit representation of the pial surface, which was then divided into distinct cortical regions. The parcellation procedure labeled cortical sulci and gyri to 68 cortical regions (i.e., 'parcels') (Fischl et al. 2004b; Desikan et al. 2006), from which cortical volumes were calculated. Cortical volumes of the frontal, temporal, parietal, occipital, and insular cortex (i.e., 'superparcels') of both the left and right hemisphere were calculated as the sum of the volumes of each parcel falling within each superparcel (Table 1).

\section{White matter: diffusion—weighted image processing}

We performed quality checks on each diffusion-weighted imaging volume using Explore DTI (Leemans 2009). As recommended by Tournier et al. (2011), we inspected the volumes in three orthogonal views (sagittal, coronal, and frontal) to identify visible artifacts, such as large signal dropouts and geometric distortions. When an artifact was detected in an isolated volume, this volume was removed. For seven participants, one to a maximum of five isolated volumes was removed. One participant moved the head with more than $2 \mathrm{~mm}$ translation and/or $2^{\circ}$ rotation in the 17 th assembled volume. Therefore, all prior assembled volumes were removed (16/61) before the movement onset, making sure that at least $2 / 3$ of all volumes remained.

After the quality checks, diffusion-weighted data were further preprocessed using the FMRIB (Functional MRI of the Brain) Software Library, FSL (Oxford University, Oxford, UK; http://www.fmrib.ox.ac.uk/fsl) (Smith et al. 2004; Woolrich et al. 2009; Jenkinson et al. 2012). For each participant, eddy-current-induced geometric distortions and head movements were corrected. Then, the diffusion-weighted volumes were corrected for distortions as a result of magnetic field inhomogeneities using fieldmap correction and were aligned to their corresponding nondiffusion-weighted (b0) image. The gradient direction table was adjusted to account for rigid transformations resulting from motion and eddy-current corrections. Subsequently, the diffusion-weighted images were brain-extracted using BET (Smith 2002), and a diffusion tensor model was fitted to each voxel using DTIfit procedure of the FMRIB's Diffusion Toolbox. This procedure outputs whole-brain FA and MD images, and additionally provides three eigenvalues of the diffusion tensor model $(\kappa 1, \kappa 2$, and $\kappa 3)$. From these eigenvalues, images of apparent diffusivities in the directions parallel (i.e., axial diffusivity $(\mathrm{AD})=\kappa 1$ ) and perpendicular (i.e., radial diffusivity $(\mathrm{RD})=(K 2+\kappa 3) / 2)$ to the $\mathrm{WM}$ tracts were created (Kumar et al. 2013).

\section{Statistical analysis}

\section{Behavioral analyses}

For unperturbed precision stepping trials, age-related changes in unperturbed step error and variability were assessed via bivariate Pearson correlation analyses (twotailed). For perturbed trials, we additionally included the effect of ARD on perturbed step error and variability; hence, a repeated measures ANCOVA with age as a covariate and $\mathrm{ARD}$ as a within-subject factor was used. Level of significance was set at $p<0.05$ for all statistical tests.

\section{Imaging analyses}

Grey matter Associations between volumes of cortical GM regions of interest (ROIs) from both hemispheres (i.e., the frontal, parietal, temporal, occipital and insular superparcels, as well as all the 68 parcels), and step error and variability of unperturbed and perturbed steps, were assessed using Pearson correlations. Since it has been proposed that approximately $95 \%$ of maximal brain size is reached by the age 6 years, we assumed that differences in GM volume were most likely due to ongoing cortical maturational processes, rather than normal physical growth (Lenroot and Giedd 2006). However, to account for such a possible underlying process, we additionally performed the correlations while correcting for total intracranial volume (ICV). Furthermore, we tested the correlations while controlling

Table 1 Superparcel formation for cortical GM measurements (used with approval of Chalavi et al. 2015)

\begin{tabular}{ll}
\hline Superparcel name & Cortical parcels \\
\hline Frontal & $\begin{array}{r}\text { Caudal and rostral middle frontal, lateral and medial orbito frontal, pars opercularis, pars triangula- } \\
\text { ris and pars orbitalis of the inferior frontal, paracentral, precentral, superior frontal, frontal pole, } \\
\text { caudal and rostral anterior cingulate }\end{array}$ \\
$\begin{array}{l}\text { Parietal } \\
\text { Temporal }\end{array}$ & $\begin{array}{l}\text { Superior, middle and inferior temporal, temporal pole, transverse temporal, banks of the superior } \\
\text { temporal sulcus, parahippocampal, entorhinal, fusiform }\end{array}$ \\
Occipital & $\begin{array}{l}\text { Lateral occipital, cuneus, lingual, peri-calcarine } \\
\text { Insula }\end{array}$ \\
Insula
\end{tabular}


for age, to identify possible variance in the relationship that could not be accounted for by age. The resulting $p$ values were corrected for multiple comparisons using the false discovery rate (FDR; $q<0.05$ ) per dependent variable (unperturbed and perturbed step error and variability) and including all superparcels (frontal, parietal, temporal, occipital, and insula) or the parcels belonging to each superparcel, per hemisphere (Benjamini and Cohen 2017; Drijkoningen et al. 2017).

White matter Voxelwise statistical analyses of the FA, MD, $\mathrm{RD}$, and AD measures were performed using TBSS (TractBased Spatial Statistics; Smith et al. 2006), part of FSL (Smith et al. 2004). Our rationale for applying TBSS was its robustness to systematic differences between participants, such as differences in brain size and developmental stage. It allows for statistical testing which is less affected by potential misalignment, and thereby provides more objective results (Smith et al. 2006). This method is appropriate for the analysis of large white-matter bundles, thereby excluding superficial white matter consisting of short-range association bundles. All participants' FA data were aligned to a common space using the nonlinear registration tool FNIRT (Smith et al. 2004; Woolrich et al. 2009; Jenkinson et al. 2012), which uses a b-spline representation of the registration warp field (Rueckert et al. 1999). The mean FA image was created and thinned to create a mean FA skeleton which represents the centers of all tracts common to the group. Each participant's aligned diffusion data (FA, MD, RD, and AD) was then projected onto this skeleton. Demeaned step error and variability of unperturbed and perturbed steps were correlated against WM microstructural measures, both with and without age (demeaned) included as a covariate of no interest. For this, we used voxelwise cross-participant statistics (Randomize, 5000 permutations; Winkler et al. 2014) with threshold-free cluster enhancement (TFCE). TFCE is a method of finding clusters in the data (Smith and Nichols 2009). The Johns Hopkins University (JHU) tractography atlas was used to identify significant voxels.

\section{Results}

\section{Behavioral results}

\section{Unperturbed precision stepping}

No correlations were found between unperturbed step error and age $(r(29)=0.300, p=0.114)$, indicating that overall unperturbed step error was not different across the studied age span (Fig. 2a). However, step variability of unperturbed steps decreased with age $(r(29)=-0.618, p<0.001)$. More specifically, older participants performed the task with higher consistency than younger participants (Fig. 2b).

\section{Perturbed precision stepping}

Perturbed step error was not different across participants of all ages $\left(F_{(1,28)}=0.729, p=0.400\right)$ (Fig. 2a). The step error seemed to decrease at smaller ARD, but there was a large variability and the changes were not significant $\left(F_{(1.460,40.885)}=1.557, p=0.224\right)$. Moreover, no interaction between ARD and age was found $\left(F_{(1.460,40.885)}=1.557, p=0.224\right)$. For variability of perturbed trials, values decreased with age $\left(F_{(1,28)}=15.053\right.$, $p=0.001)$ (Fig. 2b). Moreover, no significant effect of ARD $\left(F_{(2.489,69.687)}=0.904, p=0.428\right)$ or interaction between ARD and age was found $\left(F_{(12.489,69.687)}=0.607, p=0.612\right)$
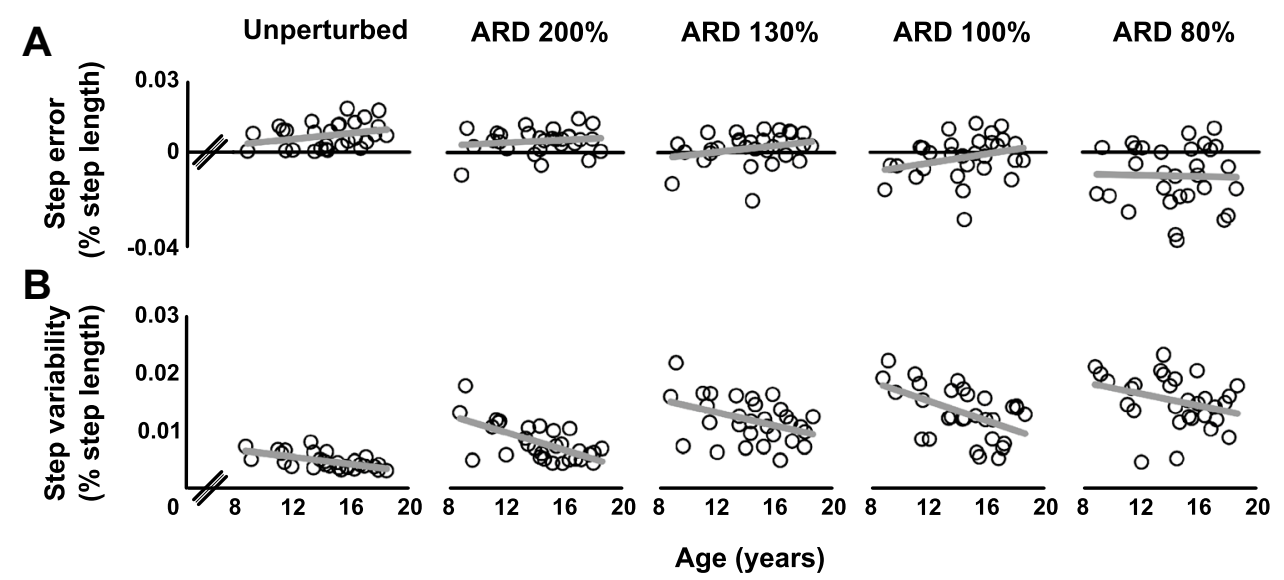

Fig. 2 Precision stepping performance on unperturbed and perturbed step targets. Step error (a) did not significantly change with age or ARD (available response distance) in both unperturbed and perturbed precision stepping. Step variability (b) significantly decreased with

age in both unperturbed and perturbed precision stepping. Moreover, a trend was found for increasing variability at shorter ARDs, albeit that these changes were non-significant. Each open circle represents a participant. Regression lines are displayed in grey 
on step variability in perturbed trials. This indicated that the consistency of the foot placements onto the step targets in the perturbed condition was not significantly affected by decreasing ARDs (nevertheless, Fig. 2b clearly shows a tendency towards larger variability at smaller ARDs).

ARD did not significantly influence perturbed step error or variability (i.e., no main effect of ARD or age $\times$ ARD interaction was found). Guided by these behavioral results, the separate analyses of ARD conditions in combination with neural measures were no longer considered informative. Therefore, we subsequently averaged the step error and variability measures over all ARD conditions into two summary measures. These summary measures were subsequently fed into the statistical models used for detecting neural contributors to gait performance. By averaging across the ARD conditions, we were able to increase the statistical power and reduce the probability of Type I errors in these subsequent GM and WM analyses.

\section{Grey matter}

Total ICV did not correlate with age $(r(26)=-0.159$, $p=0.420$, Fig. 3), suggesting that maximal head size was reached in our sample (Lenroot and Giedd 2006). However, whole-brain GM volume decreased with age $(r(26)$ $=-0.423, p=0.025)$, confirming the generally observed ongoing maturation of GM during childhood (Lenroot and Giedd 2006) (Fig. 3).

No significant correlations were found between GM volumes of superparcels (frontal, parietal, temporal, occipital, and insula) from either the left or right hemisphere and unperturbed or perturbed step error or variability $(q>0.05)$, with or without controlling for ICV or age.

When assessing the relationship between each parcel within a superparcel and step performance, step variability in unperturbed precision stepping showed significant positive correlations with GM volume of the banks of

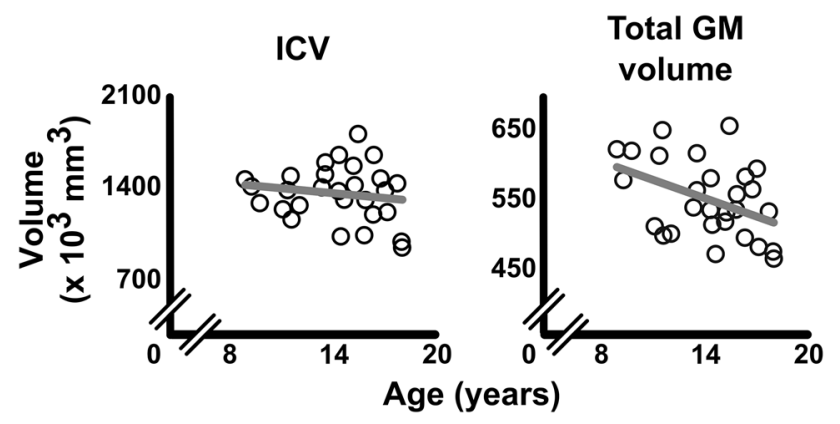

Fig. 3 Age-related changes in ICV and total GM volume. Total intracranial volume (ICV) did not correlate with age (left), while whole-brain GM volume (right) did decrease with age $(r=-0.423$, $p=0.025)$. Each open circle represents a participant. Correlation lines are displayed in grey

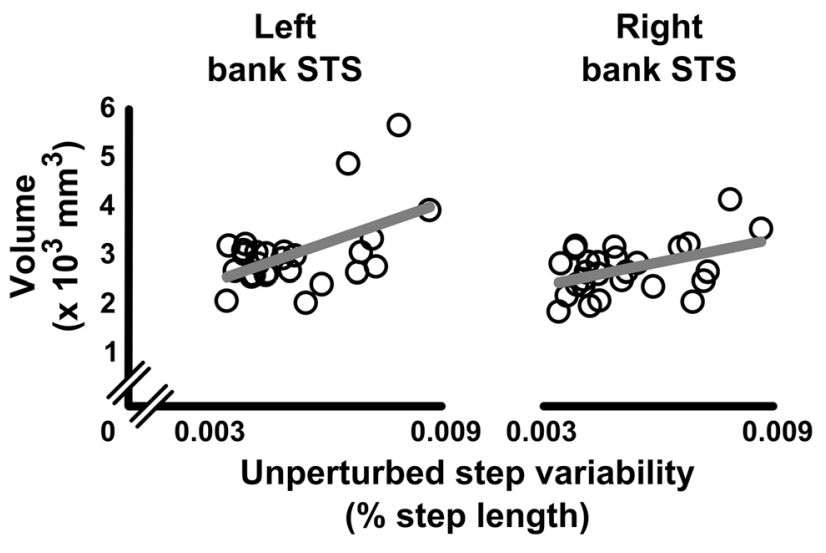

Fig. 4 Relationships between unperturbed step variability and cortical GM volume of the banks of the STS. Lower cortical GM volumes of the banks of the superior temporal sulcus (bank STS) of both the left $(r=0.528, p=0.005)$, and right $(r=0.461, p=0.016)$ hemispheres were associated to lower unperturbed step variability. These correlations remained significant after controlling for ICV (left: $p=0.004$; right: $\mathrm{p}=0.002$ ), but disappeared after controlling for age $(p>0.05)$. Each open circle represents a participant. Correlation lines are displayed in grey

the superior temporal sulcus (bankSTS) in both the left $(r(25)=0.528, p=0.005, q=0.042)$ and right hemisphere $(r(25)=0.461, p=0.016, q=0.141)$ (Fig. 4). These correlations remained significant after controlling for ICV (left: $r(24)=0.551, p=0.004, q=0.032$; right: $r(24)=0.589$, $p=0.002, q=0.014)$, but disappeared after controlling for age. Step error of unperturbed precision stepping showed a significant negative correlation with GM volume of the superior temporal cortex $(r(25)=-0.576, p=0.002, q=0.015)$ and insula $(r(25)=-0.383, p=0.048, q=0.048)$ in the right hemisphere. However, these associations disappeared after controlling for ICV or age. No significant associations were found between step error of perturbed precision stepping and parcel volumes (all $q>0.05$ ).

\section{White matter}

Whole-brain voxelwise statistical analyses revealed associations between lower unperturbed step error and higher levels of FA in the forceps minor (FM; peak voxel MNI $x=$ $-7, y=18, z=19$ ), left anterior thalamic radiation (ATR; MNI - 23, 31, 14), left superior longitudinal fasciculus (SLF; MNI - 45, 16, 16), left inferior longitudinal fasciculus (ILF; MNI - 46, - 9, - 13), and left cingulum (MNI -9, $-60,26)$ (Fig. 5). When age was not controlled, associations between unperturbed step error and FA remained significant in voxels located within the forceps minor (MNI 5, 14, 20) and left ATR (MNI -23, 31, 15). Furthermore, higher RD values in voxels within the forceps minor (MNI $-4,20$, 


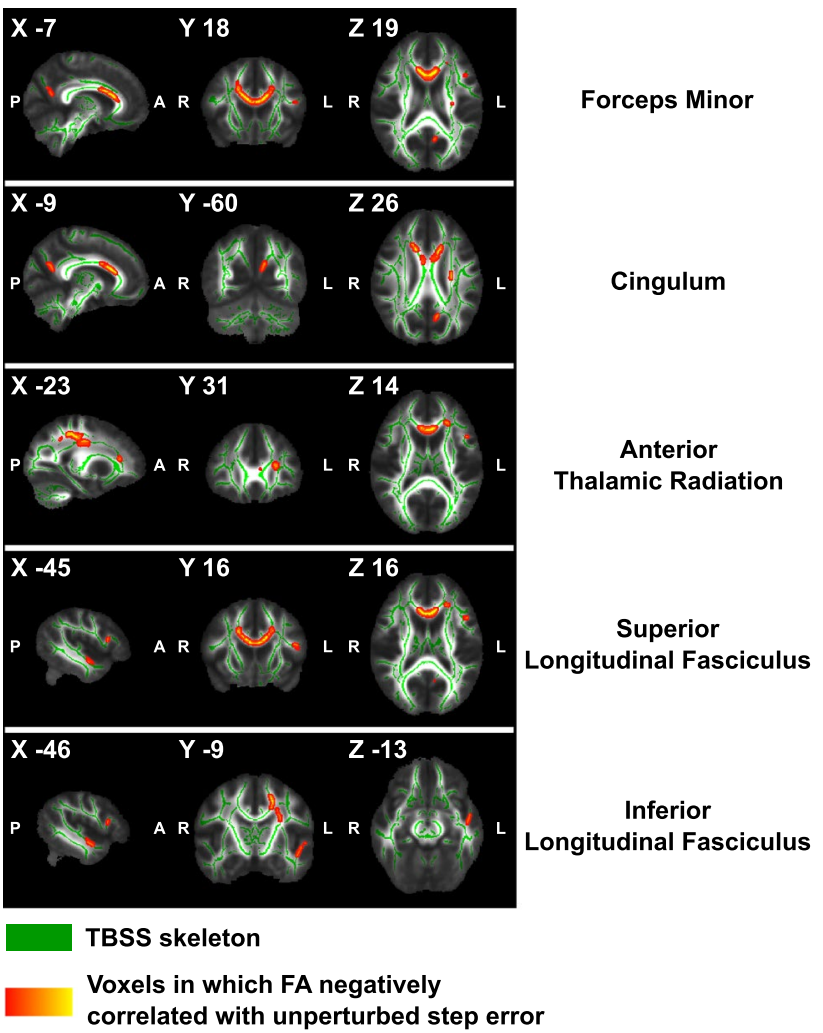

Fig. 5 Negative correlations between fractional anisotropy and unperturbed step error. Voxels of which the FA values showed a significant negative correlation with unperturbed step error are displayed (redyellow) onto a TBSS skeleton (green). These voxels resided in the forceps minor, left anterior thalamic radiation, left superior and inferior longitudinal fasciculus, and left cingulum. Labels by JHU Whitematter Tractography Atlas. Results are controlled for age

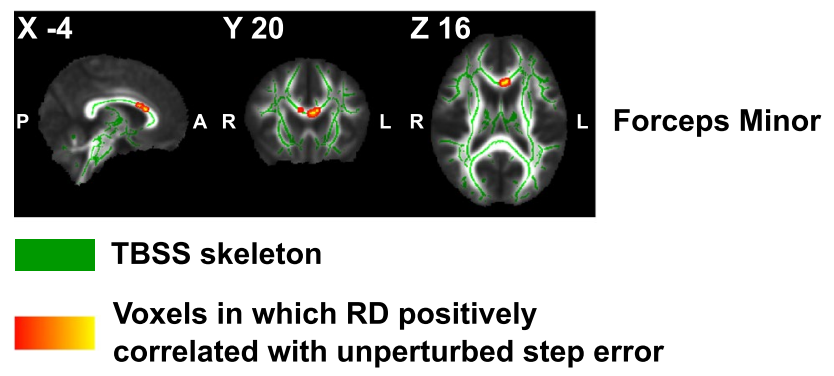

Fig. 6 Positive correlations between radial diffusivity and unperturbed step error. Voxels of which the RD values showed a significant positive correlation with unperturbed step error are displayed (red-yellow) onto a TBSS skeleton (green). These voxels resided in the forceps minor. Labels by JHU White-matter Tractography Atlas. Results are controlled for age

16) were related to larger unperturbed step error when age was controlled (Fig. 6). However, no significant correlations were found with RD values when age was not controlled.
$\mathrm{MD}$ and $\mathrm{AD}$ values showed no significant associations with unperturbed step error (with or without controlling for age). In addition, FA, MD, RD, and AD were not significantly associated with perturbed step error, or (un)perturbed step variability (with or without controlling for age).

\section{Discussion}

This exploratory study aimed to investigate the potential relationship between structural brain properties and complex gait performance in youth aged 9-18 years. We utilized a treadmill-based precision stepping task to investigate complex gait performance, and volumetric analyses of cortical GM and whole-brain voxelwise statistical analyses of WM to investigate brain maturation. As hypothesized, (un)perturbed step variability decreased with age, yet there was no significant effect of the level of task complexity on perturbed step variability. Moreover, (un)perturbed step error was not significantly correlated with age or level of complexity. On the neural level, lower GM volumes of the banks of the superior temporal sulcus were associated with decreased unperturbed step variability, yet no GM associations were found for perturbed step accuracy. Furthermore, increased WM organization of tracts, connecting higher level brain regions, were associated with decreased unperturbed step error, beyond the general age effect. These results partly confirmed our hypothesis that advanced maturation of GM and WM structures is beneficial for precision stepping accuracy. However, our study was explorative in nature, and future studies are needed to confirm our findings.

\section{Neurobehavioral associations with step variability}

As hypothesized, our results showed that the variability of foot placements on step targets decreases with age, both when the targets were placed on regular positions (unperturbed), and when they randomly shifted forwards (perturbed). These results support the findings of previous studies in healthy young participants (with ages ranging from 1 to 3 years to $10-17$ years), showing decreases in variability of spatiotemporal gait parameters during basic gait (e.g., step length, step speed, double and single-support times) (Hausdorff et al. 1999; Vaughan et al. 2003; Dusing and Thorpe 2007; Froehle et al. 2013; Muller et al. 2013; Bisi and Stagni 2016; Gouelle et al. 2016; Manicolo et al. 2016). Moreover, during complex gait (e.g., obstacle avoidance tasks), age-related reductions have been reported for variability in foot clearances, take-off and landing distances, and muscular activations (McFadyen et al. 2001; Berard and Vallis 2006; Stern and Gottschall 2012; Corporaal et al. 2016). The origin of this motor variability may lie within any level 
of the motor pathway, from central processes (e.g., motor planning) to noise in peripheral processes (e.g., force production by muscles) (van Beers 2009; Dhawale et al. 2017).

In our study, we particularly focused on the possible role of the central processes (i.e., structural brain maturation), rather than on the peripheral components. Here, we hypothesized that structural GM and WM maturation of higher order brain regions would relate to improvements of step accuracy. Although results showed no relationship between WM organization and (un)perturbed step variability, regional GM volumes of the bilateral banks of the STS were positively associated with unperturbed step variability (but not with perturbed step variability; see "neural mechanisms of perturbed stepping", below). Regarding the potential specific role of the STS in gait, functional MRI studies showed that the superior temporal sulcus deactivates during gait, as compared to quiet stance or gait imagery (Jahn et al. 2004; la Fougere et al. 2010). This deactivation is suggested to prevent unwanted movement corrections resulting from reflexive mechanisms for balance correction (Brandt et al. 1998; Jahn et al. 2004; la Fougere et al. 2010). As our precision stepping task was highly visually cued, it is plausible that brain regions regulating multisensory integration affected performance on this task. Moreover, the superior temporal sulcus is one of the latest regions in the temporal lobe to reach maturity (Lenroot and Giedd 2006). It is, however, important to note that the association between unperturbed step variability and GM volume of the banks of the STS disappeared when controlling for age. The banks of the STS lie within the multisensory vestibular cortex, together with the posterior insula, retroinsular region, and inferior parietal lobule (Dieterich and Brandt 2008), and are known to be involved in multisensory processing (i.e., vestibular, visual, auditory, and somatosensory information) (Calvert 2001; Wright et al. 2003; Beauchamp et al. 2004, 2008; van Atteveldt et al. 2004; Noesselt et al. 2007). Therefore, the effect of GM volume of the banks of the STS on gait variability might be better explained by general maturational processes, which are necessary to perform complex sensorimotor tasks, including complex gait. These GM maturational processes are thought to be driven by different biological processes, such as synaptic arborization, synaptic pruning, and axonal myelination (Lenroot and Giedd 2006). These processes generally increase the effectiveness of cortical neural processing. Although our volumetric analysis does not reveal which specific mechanism supports this GM change, it suggests a possible association between GM maturation of the STS and gait performance in our population.

It has been suggested that motor variability reflects the execution of a motor plan, rather than the creation of a motor plan, and would, therefore, originate from 'noisy' peripheral components, rather than central components of the motor system (Gouelle et al. 2013, 2016). This is in line with our results, showing no associations between step variability and structural brain differences in GM regions, or WM pathways, associated with motor planning (e.g., frontal regions, motor regions, and SMA). Possibly, peripheral sources contributed to age-related step variability in our sample such as noisy peripheral efferent and afferent pathways (Muller et al. 1994; McFadyen et al. 2001) or decreased corporeal awareness due to rapidly changing anthropometrics (Froehle et al. 2013). It is noteworthy, however, that structural brain maturation does not per se occur simultaneously with functional brain maturation (Supekar et al. 2010). For example, maturation of structural connectivity might be completed, while cortical activations and functional connectivity are still immature (Supekar et al. 2010; Cignetti et al. 2017). Therefore, inferences on functional associations between brain regions and precision stepping performance, based on our results should be made with caution.

\section{Neurobehavioral associations with step error}

Although we hypothesized that step error would decrease with age, our results showed an absence of age-related differences in step error during both unperturbed and perturbed precision stepping. These findings seemingly contrast to the previous studies on other tasks involving complex gait, showing that gait strategies improved from childhood into adolescence (Pryde et al. 1997; McFadyen et al. 2001; Berard and Vallis 2006; Corporaal et al. 2016). Specifically, when children planned and executed their own avoidance strategies, age-related differences in gait patterns and avoidance success rates emerged (e.g., changes in step length, width, and speed, and foot placements and toe clearances relative to the obstacle). An important difference between these studies and our current experiment is that time pressure was present in the current study but much less in these previous studies. Moreover, these studies allowed free choice of avoidance strategies, and thus free choice of foot placements, while we constrained foot placements to predefined locations instead. Therefore, participants were not required to define a new, anticipatory gait strategy per se, but rather had to initiate fast goal-directed movements, based on external visual cues (i.e., the step targets).

Our results imply that the ability to perform goal-directed movements with the lower limbs is mature around the age of 8 years. Similarly, Choi et al. (2016) revealed stable, adult-like step accuracy on step targets in children aged 11-16 years (comparable to our sample of 9-18 years). These authors did, however, show decreasing step accuracy in younger children aged 6-10 years. This suggests that the maturation of processes underlying goal-directed movements of the lower limbs is not completed until approximately the age of 10 years. These results are consistent with the developmental trend found for manual goal-directed 
movements, showing that adult-like movements emerge around 8-11 years of age (Yan et al. 2000; Contreras-Vidal et al. 2005; Contreras-Vidal 2006; Favilla 2006; Kagerer and Clark 2014). Considering the findings of these studies, it may be suggested that cued goal-directed behavior (as used in precision stepping) matures earlier in life (around the age of 8-10 years) as compared to anticipatory planning behavior (e.g., free strategy selection during anticipated obstacle avoidance) which seems to mature at a more advanced age. Furthermore, we hypothesized that precision step error would decrease with more mature GM and WM brain structures. Results revealed no associations between GM volumes and step error in (un)perturbed precision stepping. WM microstructural organization, however, did reveal associations with unperturbed step error in the forceps minor, left anterior thalamic radiation, cingulum, and left superior, and inferior longitudinal fasciculus (but not for perturbed precision stepping error; see "Neural mechanisms of perturbed stepping", below). Importantly, these results were particularly significant after controlling for age, which suggests that these brain-behavior associations were present beyond general maturation processes. These WM pathways are known to provide widespread reciprocal connections between several brain regions such as frontal, temporal, parietal, and occipital regions. Improved microstructural organization of these pathways has previously been associated with better performance on several spatiotemporal gait parameters (e.g., gait stability, stride length, single-support times, and gait speed), or specific gait tests (e.g., the timed up-and-go task or the number of steps while turning) in patients suffering from hydrocephalus and Alzheimer's Disease (Marumoto et al. 2012) or Dementia (Scherder et al. 2011) and in older adults (Scherder et al. 2011; Marumoto et al. 2012; Bolandzadeh et al. 2014; Bruijn et al. 2014; Verlinden et al. 2016; Seiler and Pirpamer 2017). For example, the forceps minor (connecting bilateral prefrontal cortices) has previously been associated with gait speed (Seiler and Pirpamer 2017) and abnormal gait scores on a Tinetti gait assessment (Bhadelia et al. 2009) in older adults. In addition, these WM pathways have been associated with several cognitive functions. The forceps minor has been associated with visuomotor speed, memory, and executive function (Biesbroek et al. 2016), the SLF with attention, visuospatial ability, and sensorimotor integration (Makris et al. 2005; Turken et al. 2008; Scherder et al. 2011; Vestergaard et al. 2011; Chaddock-Heyman et al. 2013; Klarborg et al. 2013; Kamali et al. 2014; RodriguezHerreros et al. 2015; Urger et al. 2015; Amemiya and Naito 2016), and the ATR with spatial information processing, movement initiation, and planning (Scherder et al. 2011).

Since end-point accuracy of precision steps has been shown to require profound visuospatial attention (e.g., Smid and den Otter 2013; Hollands et al. 1995), it is, therefore, plausible that tracts involved in such functions show associations with precision step error in our task (Patla and Vickers 1997, 2003; Higuchi 2013; Koenraadt et al. 2014). Importantly, the WM associations with unperturbed precision step error that were found in our study were particularly present after we controlled for age-related variations in WM characteristics (i.e., by including age as covariate of no interest). This demonstrates that these associations were possibly not driven by WM differences related to age, but rather to normal WM heterogeneity within the population. These results, therefore, substantiate the assumption that age-related structural brain differences do not primarily predict goal-directed precision stepping performance in our sample. It has been shown, however, that age-related structural brain changes are ongoing in the age range considered in this study (Giedd et al. 1999; Gogtay et al. 2004; Lenroot and Giedd 2006; Raznahan et al. 2011; Yap et al. 2013; Ducharme et al. 2016) and it can, therefore, not be ruled out completely that structural brain maturation has no (direct or mediating) role in gait performance. For instance, in children aged 5-17 years, age-related changes in the SLF have been associated with improved cognitive functions such as set-shifting and attention (Urger et al. 2015), which is assumed to play a role in the visually cued task examined here. Functional compensatory mechanisms may attenuate the relationship between structural maturity and behavioral outcome, such as in older adults (Heuninckx et al. 2008; Goble et al. 2010). Future studies may shed light on these possible compensatory mechanisms in children.

\section{Neural mechanisms of perturbed stepping}

We hypothesized that the impact of age-related structural brain changes in higher order cortical regions on stepping accuracy would be stronger in perturbed as compared to unperturbed precision stepping. As briefly mentioned above, however, we found no associations between GM or WM maturation and perturbed precision stepping accuracy, whereas we did for unperturbed stepping.

A recent review on the neural control of fast gait adjustments by Potocanac and Duysens (2017) suggested that fast motor responses to perturbations in the environment likely engage different neural mechanisms than unperturbed environments (Weerdesteyn et al. 2004; Reynolds and Day 2005; Potocanac et al. 2014; Hoogkamer et al. 2015; Mazaheri et al. 2015). For instance, Weerdesteyn et al. (2004) showed that when sudden obstacles had to be avoided, this provoked faster than voluntary responses, suggesting involvement of 'fast' subcortical rather than 'slow' cortical pathways. This was substantiated by findings of Marigold et al. (2007), who showed that re-direction of visual gaze towards an obstacle does not always occur when responding to its unpredictable appearance. These findings suggest that the production of fast stepping responses may require less cortical processing 
(e.g., of visuospatial information) than preplanned stepping responses. Possibly, other neural mechanisms (e.g., subcortical) may be involved. If these observations translate to our precision stepping task, it may be that the impact of maturational processes of cortical brain structures is smaller for perturbed as compared to unperturbed precision stepping.

Although the present data may provide evidence for a role of subcortical processing, they should, however, not be taken as evidence that online step adjustments are entirely independent of cortical processing. It should be pointed out that online corrections normally involve a mixture of subcortical and cortical pathways. Cortical areas, such as the posterior parietal cortex, may play a supervisory role over faster subcortical routes (Glickstein 2003; Reynolds and Day 2012). In addition, there is evidence for fast cortical processing (not reaching conscious levels; see Potocanac and Duysens 2017). Possibly, these cortical involvements in online step adjustments are not of primary importance in the age group investigated in the present study. In young adults (around 25 years of age), the addition of a dual task barely affected performance in a similar perturbed precision stepping task (Mazaheri et al. 2015). In contrast, this task was more difficult to perform in older as opposed to younger adults when the task was combined with a dual task (relying on cortical resources; Mazaheri et al. 2014, 2015). It thus appears that there is a shift towards more cortical involvement in aged groups. If this also applies to young participants, increased cognitive involvement may overcome the adverse effects of suboptimal cortical structures on behavior, similar to compensatory mechanisms on motor control in older adults (Heuninckx et al. 2008; Goble et al. 2010). Future studies may be able to shed light on the interplay between functional and structural cognitive involvement in the online adjustments of steps.

\section{Limitations}

This study aimed to explore the relationship between structural brain maturation and complex gait performance in a population of 9-18 years. It has to be noted that many developmental changes take place during this age period. Aside from structural brain maturation, for example, also functional brain development is ongoing. Furthermore, lower levels of the CNS are developing and the musculoskeletal system is changing. These changes may decrease corporeal awareness due to rapidly changing anthropometrics (Froehle et al. 2013). Although we controlled for differences in body size by normalizing our gait parameters to individual's body proportions (Hof 1996; Vaughan et al. 2003), we cannot completely rule out the possibility that developmental processes other than structural brain properties may have influenced our results. On the other hand, structural brain maturation may have impacted other sensorimotor processes, which (in)directly affected gait performance. Thus, complex sensorimotor coordination, irrespective of the specific motor task, should be investigated beyond the typical structural brain maturation analyses. Therefore, our results should be interpreted with caution, and should be used as preliminary evidence for a potential relationship between gait maturation and brain maturation. Future research may adopt an approach in which multiple developmental processes are considered as potential mediators for gait development.

\section{Conclusion}

Both unperturbed and perturbed precision stepping mature surprisingly fast as expressed by an absence of significant age-related changes in step error. Variability, however, does decrease with age and this may indicate the presence of slower maturational processes. In addition, the present study has provided, for the first time, preliminary insights into the potential link between structural brain properties and precision stepping performance in youth. For unperturbed precision stepping, the precision step error was associated with WM microstructural organization of pathways involved in attentional and visual processing. Such correlations were absent for perturbed precision stepping, requiring online adjustments of steps. This difference is consistent with the viewpoint that the neural control may differ, in particular pointing to a dominant role for fast pathways in online corrections, possibly involving subcortical circuits.

\section{Compliance with ethical standards}

Funding Sharissa H.A. Corporaal, Jolien Gooijers, and Matthieu P. Boisgontier are supported by the Research Foundation - Flanders (FWO). Sjoerd M. Bruijn was funded by a grant from The Netherlands Organization for Scientific Research (NWO \#451-12-041). Stephan P. Swinnen is supported by the KU Leuven Research Fund (C16/15/070), FWO (G.0708.14), and the Interuniversity Attraction Poles Program initiated by the Belgian Science Policy Office (P7/11). Jacques Duysens is funded by FWO (G.0901.11), and is also recipient of a CNPq Visiting Professor Grant (400819/2013-9).

Conflict of interest The authors declare that they have no conflict of interest.

Informed consent Informed consent was obtained from all individual participants included in the study and their parents. Participants were financially compensated for participation.

Ethical approval All procedures performed in studies involving human participants were in accordance with the ethical standards of the local ethics committee of the KU Leuven, Belgium, and with the 1964 Helsinki declaration and its later amendments or comparable ethical standards. 
Open Access This article is distributed under the terms of the Creative Commons Attribution 4.0 International License (http://creativecommons.org/licenses/by/4.0/), which permits unrestricted use, distribution, and reproduction in any medium, provided you give appropriate credit to the original author(s) and the source, provide a link to the Creative Commons license, and indicate if changes were made.

\section{References}

Amemiya K, Naito E (2016) Importance of human right inferior frontoparietal network connected by inferior branch of superior longitudinal fasciculus tract in corporeal awareness of kinesthetic illusory movement. Cortex 78:15-30

Beauchamp MS, Lee KE, Argall BD, Martin A (2004) Integration of auditory and visual information about objects in superior temporal sulcus. Neuron 41:809-823

Beauchamp MS, Yasar NE, Frye RE, Ro T (2008) Touch, sound and vision in human superior temporal sulcus. Neuroimage 41:1011-1020

Beauchet O, Annweiler C, Celle S, Bartha R, Barthelemy JC, Roche F (2014) Higher gait variability is associated with decreased parietal gray matter volume among healthy older adults. Brain Topogr 27:293-295

Benjamini Y, Cohen R (2017) Weighted false discovery rate controlling procedures for clinical trials. Biostatistics 18:91-104

Berard JR, Vallis LA (2006) Characteristics of single and double obstacle avoidance strategies: a comparison between adults and children. Exp Brain Res 175:21-31

Bhadelia RA, Price LL, Tedesco KL, Scott T, Qiu WQ, Patz S, Folstein M, Rosenberg I, Caplan LR, Bergethon P (2009) Diffusion tensor imaging, white matter lesions, the corpus callosum, and gait in the elderly. Stroke 40:3816-3820

Biesbroek JM, Weaver NA, Hilal S, Kuijf HJ, Ikram MK, Xu X, Tan BY, Venketasubramanian N, Postma A, Biessels GJ, Chen CP (2016) Impact of strategically located white matter hyperintensities on cognition in memory clinic patients with small vessel disease. PLoS One 11:e0166261

Bisi MC, Stagni R (2016) Development of gait motor control: what happens after a sudden increase in height during adolescence? Biomed Eng Online 15:47

Bolandzadeh N, Liu-Ambrose T, Aizenstein H, Harris T, Launer L, Yaffe K, Kritchevsky SB, Newman A, Rosano C (2014) Pathways linking regional hyperintensities in the brain and slower gait. Neuroimage 99:7-13

Brandt T, Bartenstein P, Janek A, Dieterich M (1998) Reciprocal inhibitory visual-vestibular interaction. Visual motion stimulation deactivates the parieto-insular vestibular cortex. Brain 121(Pt 9):1749-1758

Bruijn SM, Van Impe A, Duysens J, Swinnen SP (2014) White matter microstructural organization and gait stability in older adults. Front Aging Neurosci 6:104

Calvert GA (2001) Crossmodal processing in the human brain: insights from functional neuroimaging studies. Cereb Cortex 11:1110-1123

Casey BJ, Tottenham N, Liston C, Durston S (2005) Imaging the developing brain: what have we learned about cognitive development? Trends Cogn Sci 9:104-110

Chaddock-Heyman L, Erickson KI, Voss MW, Powers JP, Knecht AM, Pontifex MB, Drollette ES, Moore RD, Raine LB, Scudder MR, Hillman CH, Kramer AF (2013) White matter microstructure is associated with cognitive control in children. Biol Psychol 94:109-115
Chalavi S, Vissia EM, Giesen ME, Nijenhuis ERS, Draijer N, Barker GJ, Veltman DJ, Reinders AATS. (2015) Similar cortical but not subcortical gray matter abnormalities in women with posttraumatic stress disorder with versus without dissociative identity disorder. Psychiat Res-Neuroim 231:308-319

Choi JT, Jensen P, Nielsen JB (2016) Locomotor sequence learning in visually guided walking. J Neurophysiol 115:2014-2020

Cignetti F, Fontan A, Menant J, Nazarian B, Anton JL, Vaugoyeau M, Assaiante C (2017) Protracted development of the proprioceptive brain network during and beyond adolescence. Cereb Cortex 27:1285-1296

Contreras-Vidal JL (2006) Development of forward models for hand localization and movement control in 6- to 10-year-old children. Hum Mov Sci 25:634-645

Contreras-Vidal JL, Bo J, Boudreau JP, Clark JE (2005) Development of visuomotor representations for hand movement in young children. Exp Brain Res 162:155-164

Corporaal SH, Swinnen SP, Duysens J, Bruijn SM (2016) Slow maturation of planning in obstacle avoidance in humans. $\mathrm{J}$ Neurophysiol 115:404-412

Dale AM, Sereno MI (1993) Improved localizadon of cortical activity by combining EEG and MEG with MRI cortical surface reconstruction: a linear approach. J Cogn Neurosci 5:162-176

Dale AM, Fischl B, Sereno MI (1999) Cortical surface-based analysis. I. Segmentation and surface reconstruction. Neuroimage 9:179-194

de Laat KF, Tuladhar AM, van Norden AG, Norris DG, Zwiers MP, de Leeuw FE (2011) Loss of white matter integrity is associated with gait disorders in cerebral small vessel disease. Brain 134:73-83

Desikan RS, Segonne F, Fischl B, Quinn BT, Dickerson BC, Blacker D, Buckner RL, Dale AM, Maguire RP, Hyman BT, Albert MS, Killiany RJ (2006) An automated labeling system for subdividing the human cerebral cortex on MRI scans into gyral based regions of interest. Neuroimage 31:968-980

Dhawale AK, Smith MA, Olveczky BP (2017) The role of variability in motor learning. Annu Rev Neurosci, 40: 479-498

Dieterich M, Brandt T (2008) Functional brain imaging of peripheral and central vestibular disorders. Brain 131:2538-2552

Drijkoningen D, Chalavi S, Sunaert S, Duysens J, Swinnen SP, Caeyenberghs K (2017) Regional gray matter volume loss is associated with gait impairments in young brain-injured individuals. J Neurotrauma 34:1022-1034

Ducharme S, Albaugh MD, Nguyen TV, Hudziak JJ, Mateos-Perez JM, Labbe A, Evans AC, Karama S (2016) Trajectories of cortical thickness maturation in normal brain developmentthe importance of quality control procedures. Neuroimage 125:267-279

Dusing SC, Thorpe DE (2007) A normative sample of temporal and spatial gait parameters in children using the GAITRite electronic walkway. Gait Posture 25:135-139

Favilla M (2006) Reaching movements in children: accuracy and reaction time development. Exp Brain Res 169:122-125

Fischl B, Dale AM (2000) Measuring the thickness of the human cerebral cortex from magnetic resonance images. Proc Natl Acad Sci USA 97:11050-11055

Fischl B, Salat DH, Busa E, Albert M, Dieterich M, Haselgrove C, van der Kouwe A, Killiany R, Kennedy D, Klaveness S, Montillo A, Makris N, Rosen B, Dale AM (2002) Whole brain segmentation: automated labeling of neuroanatomical structures in the human brain. Neuron 33:341-355

Fischl B, Salat DH, van der Kouwe AJ, Makris N, Segonne F, Quinn BT, Dale AM (2004a) Sequence-independent segmentation of magnetic resonance images. Neuroimage 23(Suppl 1):S69-S84

Fischl B, van der Kouwe A, Destrieux C, Halgren E, Segonne F, Salat DH, Busa E, Seidman LJ, Goldstein J, Kennedy D, Caviness V, 
Makris N, Rosen B, Dale AM (2004b) Automatically parcellating the human cerebral cortex. Cereb Cortex 14:11-22

Forssberg H (1985) Ontogeny of human locomotor control. I. Infant stepping, supported locomotion and transition to independent locomotion. Exp Brain Res 57:480-493

Froehle AW, Nahhas RW, Sherwood RJ, Duren DL (2013) Agerelated changes in spatiotemporal characteristics of gait accompany ongoing lower limb linear growth in late childhood and early adolescence. Gait Posture 38:14-19

Giedd JN, Blumenthal J, Jeffries NO, Castellanos FX, Liu H, Zijdenbos A, Paus T, Evans AC, Rapoport JL (1999) Brain development during childhood and adolescence: a longitudinal MRI study. Nat Neurosci 2:861-863

Glickstein M (2003) Subcortical projections of the parietal lobes. Adv Neurol 93:43-55

Goble DJ, Coxon JP, Van Impe A, De Vos J, Wenderoth N, Swinnen SP (2010) The neural control of bimanual movements in the elderly: Brain regions exhibiting age-related increases in activity, frequency-induced neural modulation, and task-specific compensatory recruitment. Hum Brain Mapp 31:1281-1295

Gogtay N, Giedd JN, Lusk L, Hayashi KM, Greenstein D, Vaituzis AC, Nugent TF, 3rd, Herman DH, Clasen LS, Toga AW, Rapoport JL, Thompson PM (2004) Dynamic mapping of human cortical development during childhood through early adulthood. Proc Natl Acad Sci USA 101:8174-8179

Gouelle A, Megrot F, Presedo A, Husson I, Yelnik A, Pennecot GF (2013) The gait variability index: a new way to quantify fluctuation magnitude of spatiotemporal parameters during gait. Gait Posture 38:461-465

Gouelle A, Leroux J, Bredin J, Megrot F (2016) Changes in gait variability from first steps to adulthood: normative data for the gait variability index. J Mot Behav 48:249-255

Hamacher D, Herold F, Wiegel P, Hamacher D, Schega L (2015) Brain activity during walking: a systematic review. Neurosci Biobehav Rev 57:310-327

Hausdorff JM, Zemany L, Peng C, Goldberger AL (1999) Maturation of gait dynamics: stride-to-stride variability and its temporal organization in children. J Appl Physiol (1985) 86:1040-1047

Herting MM, Gautam P, Spielberg JM, Dahl RE, Sowell ER (2015) A longitudinal study: changes in cortical thickness and surface area during pubertal maturation. PLoS One 10:e0119774

Heuninckx S, Wenderoth N, Swinnen SP (2008) Systems neuroplasticity in the aging brain: recruiting additional neural resources for successful motor performance in elderly persons. J Neurosci 28:91-99

Higuchi T (2013) Visuomotor control of human adaptive locomotion: understanding the anticipatory nature. Front Psychol 4:277

Hof AL (1996) Scaling gait data to body size. Gait Posture 4:222-223

Hollands MA, Marple-Horvat DE, Henkes S, Rowan AK (1995) Human eye movements during visually guided stepping. J Mot Behav 27:155-163

Hoogkamer W, Potocanac Z, Duysens J (2015) Quick foot placement adjustments during gait: direction matters. Exp Brain Res 233:3349-3357

Huttenlocher PR (1990) Morphometric study of human cerebral cortex development. Neuropsychologia 28:517-527

Jahn K, Deutschlander A, Stephan T, Strupp M, Wiesmann M, Brandt $\mathrm{T}$ (2004) Brain activation patterns during imagined stance and locomotion in functional magnetic resonance imaging. Neuroimage 22:1722-1731

Jenkinson M, Beckmann CF, Behrens TE, Woolrich MW, Smith SM (2012) FSL Neuroimage 62:782-790

Kagerer FA, Clark JE (2014) Development of interactions between sensorimotor representations in school-aged children. Hum Mov Sci 34:164-177
Kamali A, Flanders AE, Brody J, Hunter JV, Hasan KM (2014) Tracing superior longitudinal fasciculus connectivity in the human brain using high resolution diffusion tensor tractography. Brain Struct Funct 219:269-281

Klarborg B, Skak Madsen K, Vestergaard M, Skimminge A, Jernigan TL, Baare WF (2013) Sustained attention is associated with right superior longitudinal fasciculus and superior parietal white matter microstructure in children. Hum Brain Mapp 34:3216-3232

Kochunov P, Williamson DE, Lancaster J, Fox P, Cornell J, Blangero J, Glahn DC (2012) Fractional anisotropy of water diffusion in cerebral white matter across the lifespan. Neurobiol Aging 33:9-20

Koenraadt KL, Roelofsen EG, Duysens J, Keijsers NL (2014) Cortical control of normal gait and precision stepping: an fNIRS study. Neuroimage 85(Pt 1):415-422

Koo BB, Bergethon P, Qiu WQ, Scott T, Hussain M, Rosenberg I, Caplan LR, Bhadelia RA (2012) Clinical prediction of fall risk and white matter abnormalities: a diffusion tensor imaging study. Arch Neurol 69:733-738

Kostovic I, Jovanov-Milosevic N, Rados M, Sedmak G, Benjak V, Kostovic-Srzentic M, Vasung L, Culjat M, Rados M, Huppi P, Judas M (2014) Perinatal and early postnatal reorganization of the subplate and related cellular compartments in the human cerebral wall as revealed by histological and MRI approaches. Brain Struct Funct 219:231-253

Kumar R, Chavez AS, Macey PM, Woo MA, Harper RM (2013) Brain axial and radial diffusivity changes with age and gender in healthy adults. Brain Res 1512:22-36

la Fougere C, Zwergal A, Rominger A, Forster S, Fesl G, Dieterich M, Brandt T, Strupp M, Bartenstein P, Jahn K (2010) Real versus imagined locomotion: a [18F]-FDG PET-fMRI comparison. Neuroimage 50:1589-1598

Lebel C, Beaulieu C (2011) Longitudinal development of human brain wiring continues from childhood into adulthood. J Neurosci 31:10937-10947

Leemans AJB, Sijbers J, Jones DK (2009) Exploredti: a graphical toolbox for processing, analyzing, and visualizing diffusion MR data. In: 17th Annual Meeting of Intl Soc Mag Reson Med. Hawaii, USA

Lenroot RK, Giedd JN (2006) Brain development in children and adolescents: insights from anatomical magnetic resonance imaging. Neurosci Biobehav Rev 30:718-729

Makris N, Kennedy DN, McInerney S, Sorensen AG, Wang R, Caviness VS Jr, Pandya DN (2005) Segmentation of subcomponents within the superior longitudinal fascicle in humans: a quantitative, in vivo, DT-MRI study. Cereb Cortex 15:854-869

Manicolo O, Grob A, Lemola S, Hagmann-von Arx P (2016) Agerelated decline of gait variability in children with attention-deficit/hyperactivity disorder: support for the maturational delay hypothesis in gait. Gait Posture 44:245-249

Marigold DS, Weerdesteyn V, Patla AE, Duysens J (2007) Keep looking ahead? Re-direction of visual fixation does not always occur during an unpredictable obstacle avoidance task. Exp Brain Res 176:32-42

Marumoto K, Koyama T, Hosomi M, Kodama N, Miyake H, Domen K (2012) Diffusion tensor imaging in elderly patients with idiopathic normal pressure hydrocephalus or Parkinson's disease: diagnosis of gait abnormalities. Fluids Barriers CNS 9:20

Mazaheri M, Roerdink M, Bood RJ, Duysens J, Beek PJ, Peper CL (2014) Attentional costs of visually guided walking: effects of age, executive function and stepping-task demands. Gait Posture 40:182-186

Mazaheri M, Hoogkamer W, Potocanac Z, Verschueren S, Roerdink M, Beek PJ, Peper CE, Duysens J (2015) Effects of aging and dual tasking on step adjustments to perturbations in visually cued walking. Exp Brain Res 233:3467-3474 
McFadyen BJ, Malouin F, Dumas F (2001) Anticipatory locomotor control for obstacle avoidance in mid-childhood aged children. Gait Posture 13:7-16

Michel J, Grobet C, Dietz V, van Hedel HJ (2010) Obstacle stepping in children: task acquisition and performance. Gait Posture 31:341-346

Muller K, Ebner B, Homberg V (1994) Maturation of fastest afferent and efferent central and peripheral pathways: no evidence for a constancy of central conduction delays. Neurosci Lett 166:9-12

Muller J, Muller S, Baur H, Mayer F (2013) Intra-individual gait speed variability in healthy children aged $1-15$ years. Gait Posture 38:631-636

Noesselt T, Rieger JW, Schoenfeld MA, Kanowski M, Hinrichs H, Heinze HJ, Driver J (2007) Audiovisual temporal correspondence modulates human multisensory superior temporal sulcus plus primary sensory cortices. J Neurosci 27:11431-11441

Oldfield RC (1971) The assessment and analysis of handedness: the Edinburgh inventory. Neuropsychologia 9:97-113

Ostby Y, Tamnes CK, Fjell AM, Westlye LT, Due-Tonnessen P, Walhovd KB (2009) Heterogeneity in subcortical brain development: A structural magnetic resonance imaging study of brain maturation from 8 to 30 years. J Neurosci 29:11772-11782

Patla AE, Vickers JN (1997) Where and when do we look as we approach and step over an obstacle in the travel path? Neuroreport 8:3661-3665

Patla AE, Vickers JN (2003) How far ahead do we look when required to step on specific locations in the travel path during locomotion? Exp Brain Res 148:133-138

Paus T (2005) Mapping brain maturation and cognitive development during adolescence. Trends Cogn Sci 9:60-68

Petanjek Z, Judas M, Kostovic I, Uylings HB (2008) Lifespan alterations of basal dendritic trees of pyramidal neurons in the human prefrontal cortex: a layer-specific pattern. Cereb Cortex 18:915-929

Potocanac Z, Duysens J (2017) Online adjustments of leg movements in healthy young and old. Exp Brain Res 235:2329-2348

Potocanac Z, Hoogkamer W, Carpes FP, Pijnappels M, Verschueren SM, Duysens J (2014) Response inhibition during avoidance of virtual obstacles while walking. Gait Posture 39:641-644

Pryde KM, Roy EA, Patla AE (1997) Age-related trends in locomotor ability and obstacle avoidance. Hum Mov Sci 16:507-516

Raznahan A, Shaw P, Lalonde F, Stockman M, Wallace GL, Greenstein D, Clasen L, Gogtay N, Giedd JN (2011) How does your cortex grow? J Neurosci 31:7174-7177

Raznahan A, Shaw PW, Lerch JP, Clasen LS, Greenstein D, Berman R, Pipitone J, Chakravarty MM, Giedd JN (2014) Longitudinal fourdimensional mapping of subcortical anatomy in human development. Proc Natl Acad Sci USA 111:1592-1597

Reuter M, Rosas HD, Fischl B (2010) Highly accurate inverse consistent registration: a robust approach. Neuroimage 53:1181-1196

Reynolds RF, Day BL (2005) Rapid visuo-motor processes drive the leg regardless of balance constraints. Curr Biol 15:R48-R49

Reynolds RF, Day BL (2012) Direct visuomotor mapping for fast visually-evoked arm movements. Neuropsychologia 50:3169-3173

Rodriguez-Herreros B, Amengual JL, Gurtubay-Antolin A, Richter L, Jauer P, Erdmann C, Schweikard A, Lopez-Moliner J, Rodriguez-Fornells A, Munte TF (2015) Microstructure of the superior longitudinal fasciculus predicts stimulation-induced interference with on-line motor control. Neuroimage 120:254-265

Roerdink M, Coolen BH, Clairbois BH, Lamoth CJ, Beek PJ (2008) Online gait event detection using a large force platform embedded in a treadmill. J Biomech 41:2628-2632

Rosano C, Aizenstein H, Brach J, Longenberger A, Studenski S, Newman AB (2008) Special article: gait measures indicate underlying focal gray matter atrophy in the brain of older adults. J Gerontol A Biol Sci Med Sci 63:1380-1388

Rosano C, Studenski SA, Aizenstein HJ, Boudreau RM, Longstreth WT Jr, Newman AB (2012) Slower gait, slower information processing and smaller prefrontal area in older adults. Age Ageing 41:58-64

Rueckert D, Sonoda LI, Hayes C, Hill DL, Leach MO, Hawkes DJ (1999) Nonrigid registration using free-form deformations: application to breast MR images. IEEE Trans Med Imaging 18:712-721

Scherder E, Eggermont L, Visscher C, Scheltens P, Swaab D (2011) Understanding higher level gait disturbances in mild dementia in order to improve rehabilitation: 'last in-first out'. Neurosci Biobehav Rev 35:699-714

Seiler S, Pirpamer L (2017) Lower magnetization transfer ratio in the forceps minor is associated with poorer gait velocity in older adults. AJNR Am J Neuroradiol 38:500-506

Sled JG, Zijdenbos AP, Evans AC (1998) A nonparametric method for automatic correction of intensity nonuniformity in MRI data. IEEE Trans Med Imaging 17:87-97

Smid KA, den Otter AR (2013) Why you need to look where you step for precise foot placement: the effects of gaze eccentricity on stepping errors.Gait Posture38:242-246

Smith SM (2002) Fast robust automated brain extraction. Hum Brain Mapp 17:143-155

Smith SM, Nichols TE (2009) Threshold-free cluster enhancement: addressing problems of smoothing, threshold dependence and localisation in cluster inference. Neuroimage 44:83-98

Smith SM, Jenkinson M, Woolrich MW, Beckmann CF, Behrens TE, Johansen-Berg H, Bannister PR, De Luca M, Drobnjak I, Flitney DE, Niazy RK, Saunders J, Vickers J, Zhang Y, De Stefano N, Brady JM, Matthews PM (2004) Advances in functional and structural MR image analysis and implementation as FSL. Neuroimage 23(Suppl 1):S208-S219

Smith SM, Jenkinson M, Johansen-Berg H, Rueckert D, Nichols TE, Mackay CE, Watkins KE, Ciccarelli O, Cader MZ, Matthews PM, Behrens TEJ (2006) Tract-based spatial statistics: voxelwise analysis of multi-subject diffusion data. Neuroimage 31:1487-1505

Sowell ER, Thompson PM, Holmes CJ, Jernigan TL, Toga AW (1999) In vivo evidence for post-adolescent brain maturation in frontal and striatal regions. Nat Neurosci 2:859-861

Stern KA, Gottschall JS (2012) Child temporal-spatial gait characteristics and variability during uphill and downhill walking. Pediatr Phys Ther 24:285-290

Supekar K, Uddin LQ, Prater K, Amin H, Greicius MD, Menon V (2010) Development of functional and structural connectivity within the default mode network in young children. Neuroimage 52:290-301

Tournier JD, Mori S, Leemans A (2011) Diffusion tensor imaging and beyond. Magn Reson Med 65:1532-1556

Turken A, Whitfield-Gabrieli S, Bammer R, Baldo JV, Dronkers NF, Gabrieli JD (2008) Cognitive processing speed and the structure of white matter pathways: convergent evidence from normal variation and lesion studies. Neuroimage 42:1032-1044

Urger SE, De Bellis MD, Hooper SR, Woolley DP, Chen SD, Provenzale $\mathbf{J}$ (2015) The superior longitudinal fasciculus in typically developing children and adolescents: diffusion tensor imaging and neuropsychological correlates. J Child Neurol 30:9-20

van Beers RJ (2009) Motor learning is optimally tuned to the properties of motor noise. Neuron 63:406-417

van Atteveldt N, Formisano E, Goebel R, Blomert L (2004) Integration of letters and speech sounds in the human brain. Neuron 43:271-282 
van Ooijen MW, Roerdink M, Trekop M, Visschedijk J, Janssen TW, Beek PJ (2013) Functional gait rehabilitation in elderly people following a fall-related hip fracture using a treadmill with visual context: design of a randomized controlled trial. BMC Geriatr $13: 34$

Vaughan CL, Langerak NG, O’Malley MJ (2003) Neuromaturation of human locomotion revealed by non-dimensional scaling. Exp Brain Res 153:123-127

Verlinden VJ, de Groot M, Cremers LG, van der Geest JN, Hofman A, Niessen WJ, van der Lugt A, Vernooij, MW, Ikram MA (2016) Tract-specific white matter microstructure and gait in humans. Neurobiol Aging 43:164-173

Vestergaard M, Madsen KS, Baare WF, Skimminge A, Ejersbo LR, Ramsoy TZ, Gerlach C, Akeson P, Paulson OB, Jernigan TL (2011) White matter microstructure in superior longitudinal fasciculus associated with spatial working memory performance in children. J Cogn Neurosci 23:2135-2146

Weerdesteyn V, Nienhuis B, Hampsink B, Duysens J (2004) Gait adjustments in response to an obstacle are faster than voluntary reactions. Hum Mov Sci 23:351-363
Winkler AM, Ridgway GR, Webster MA, Smith SM, Nichols TE (2014) Permutation inference for the general linear model. Neuroimage 92:381-397

Woolrich MW, Jbabdi S, Patenaude B, Chappell M, Makni S, Behrens T, Beckmann C, Jenkinson M, Smith SM (2009) Bayesian analysis of neuroimaging data in FSL. Neuroimage 45:S173-S186

Wright TM, Pelphrey KA, Allison T, McKeown MJ, McCarthy G (2003) Polysensory interactions along lateral temporal regions evoked by audiovisual speech. Cereb Cortex 13:1034-1043

Yan JH, Thomas JR, Stelmach GE, Thomas KT (2000) Developmental features of rapid aiming arm movements across the lifespan. $\mathrm{J}$ Mot Behav 32:121-140

Yap QJ, Teh I, Fusar-Poli P, Sum MY, Kuswanto C, Sim K (2013) Tracking cerebral white matter changes across the lifespan: insights from diffusion tensor imaging studies. J Neural Transm (Vienna) 120:1369-1395 